\title{
Information Transfer between Major Shareholders and Company Value Reduction
}

\author{
Zhongfu $\mathrm{Yu}^{1, \mathrm{a}}$, Jing $\mathrm{He}^{2, \mathrm{~b}}$ and Yalong $\mathrm{Liu}^{2, \mathrm{c}^{*}}$ \\ ${ }^{1}$ North China Electric Power University, Beijing, China; \\ ${ }^{2}$ North China Electric Power University, Beijing, China. \\ a13381107358@163.com, bjij0716@qq.com, ‘2582854255@qq.com
}

*The corresponding author

\section{Keywords: Major shareholder reduction; Corporate value; Insider trading; Information transfer}

\begin{abstract}
Based on the data of all the announcements released in the A-share market from 2012 to 2016, this paper empirically studies the relationship between the reduction of major shareholders and the valuation of the stock of the enterprise. Through regression analysis, we find that there is a positive correlation between the reduction of major shareholders and the value of Tobin Q. Through further classification tests, this paper finds that the reduction of non-state-owned major shareholders can better convey the overestimation of enterprise value Similarly, compared with a natural person shareholder, the reduction of non-natural person major shareholders is also more able to convey the information that the enterprise value is overvalued. This paper suggests that investors can refer to the reduction of non-state-owned nature of large shareholders and large shareholders of non-natural person nature to assess the value of the enterprise and support investment decisions.

Due to the special historical problems arising from the transition of China's economic system, the shares of listed companies in the A-share market were divided into tradable shares and non-tradable shares. The share splitting resulted in differences in shareholding costs and circulation rights. The listed companies and major shareholders lacked the sensitivity of the stock price rise and fall is not conducive to safeguarding the interests of small and medium shareholders, and has seriously affected the development of China's stock market. The equity division reform started in 2005 has overcome the problems of different rights of the same stocks and different interests of the same stocks in the capital market to a certain extent, but it has also pushed China's stock market to an era of great expansion, and the market price pressure has greatly increased. After the stocks of major shareholders are lifted, they also need to be concerned about price fluctuations in the stock market, which will help protect the rights and interests of minority shareholders to a certain extent. However, due to the information advantage of the "internal person" of the major shareholders, it is often possible to control the trend of stock prices before other market investors, and may use the disclosure of major information of the company to solicit the interests of small shareholders. In the period from 2008 to 2014 after the ban was lifted, the shareholding ratio of major shareholders of listed companies in China decreased by an average of $0.3801 \%$ over the previous year, and a total of 1186 major shareholders of listed companies reduced their shareholdings ${ }^{[1]}$.If we can find out the information transmitted by the reduction of major shareholder stocks, it will help many small and medium investors obtain more information and make more informed investment decisions.

The split share structure reform is the most far-reaching reform measure since the establishment of China's securities market. It has received attention from all sectors of society, especially the lifting of the ban on the restricted shares of major shareholders. Many scholars have done various studies. The main research directions are as follows: First, the discussion on the motivations and results of major shareholder reductions, such as Lin Chuan and Cao Guohua (2012) empirically examined the relationship between earnings management, non-annual report effects and major shareholder reductions. The higher the degree of earnings management of a listed company, the greater the reduction of the shareholder's efforts ${ }^{[2]}$. Chen Wei and Wu Shinong (2013) studied the reduction of holdings by senior executives and large shareholders from the aspects of financial performance, shareholding structure, market situation, and consequences of reductions, and empirically
\end{abstract}


analyzed the incentives and consequences of major shareholder reductions. ${ }^{[3]}$ Zhang Chengrui, Wang Hua, and Liang Sunning (2016) took the example of the reduction of the original shareholders after the lifting of the ban on the sale of restricted shares. After empirical analysis, it was found that the main reason for controlling shareholders to reduce their holdings was due to the lower performance of the company or the low level of the rule of law in the region. The reduction of non-controlling majority shareholders is related to the over-estimation of the company's market value, the high degree of concentration of shares, and the large scale of lifted restricted shares. ${ }^{[4]}$ The second is the study of timing and timing of major shareholder reductions, such as Deng Mingmao (2016) summarizing the timing of major shareholders' shareholding reduction in the private placement process and expounding the major shareholder's reduction in price during the private placement process. New arbitrage model ${ }^{[5]}$. Lin Zhenxing and Qu Wenzhou (2010) found that there are market opportunities for major shareholders to reduce holdings of restricted shares through the block trading system. The reduction in block trades will bring significant negative wealth effects to the auction trading market, and will be reduced to the follow-up period of stocks. The abnormal returns are significantly negatively correlated with the discount levels of the block trades. ${ }^{[6]}$ The third is the study of short selling behaviors of major shareholder reduction, such as Fu Liping and Zhang Dayong (2011), using OLS and Logistic regression methods, to empirically analyze the tunnel behavior of major shareholders through the manipulation of major information disclosure in the process of share reduction. ${ }^{[7]} \mathrm{Wu}$ Yuhui, Wu Shinong (2010) confirms the fact that large shareholders, especially controlling shareholders, control the interests of minority shareholders by controlling the disclosure of major information of listed companies through empirical research. ${ }^{[8]}$

Summarizing the existing research literature, few scholars can clearly point out the contents of corporate information that can be transmitted by major shareholder reductions, and few people can analyze the mechanism of transfer of trust reduction behavior. Although Zhu Hongjun, Li Lu, Wang Hui, and Yu Liyong (2010) found that the market reaction was negative during the announcement period and became inverted "U" type ${ }^{[9]}$. Zhu Chafen, Li Zhiwen, and Chen Chao (2011) found that the market believes that the reduction of shareholding has given rise to new information with high valuations or poor prospects. This has made a significant negative reaction. ${ }^{[10]}$ However, they have not been able to elaborate on the specific information content that the stockholders' value is higher than the company's value, which is very important for many small and medium shareholders and national regulatory agencies. This article will be based on the company data of major shareholders in all listed companies of the Shanghai and Shenzhen Stock Exchanges during the 2012-2016 period, and creatively divide the data into state-owned major shareholders and non-state-owned major shareholders in accordance with the nature of the reduction of shareholders. The two groups of natural persons and non-natural person shareholder comparative analysis, through empirical research to analyze the relationship between the major shareholder reduction behavior and corporate value overestimation.

\section{Theoretical Analysis and Research Hypothesis}

This article should first clarify the definition of major shareholders. In summary, major shareholders refer to relatively large shareholders. It indicates that the shareholder has the largest share compared with the rest of the shareholders, while the controlling shareholder refers to the large proportion of shares. To shareholders who can influence the company's daily operations and major decisions, this article focuses on the major shareholders. Jasmin Gider and Christian Westheide (2016) define insiders as a group of people who can learn more about company value information, and they have better information than outside investors, such as executives and directors. ${ }^{[1]}$ Liu Jinxing, Song Lisheng (2015) defines insider trading as the act of directors, supervisors, and senior management of listed companies buying and selling shares of the company through the secondary market. ${ }^{[12]}$ David J. Denis and Jin Xu believe that insider trading is an implicit way of compensation and incentives. ${ }^{[13]}$ By participating in or understanding the company's business decision-making activities, insiders can better obtain information on performance changes than outside investors, and therefore can more accurately grasp the company's value and future prospects. In addition, insiders 
have the advantage of insider information, earning income by knowing and influencing company announcements in advance. Lakonishok and Lee have proved through empirical research that insider buy can obtain obvious excess return ${ }^{[14]}$. According to the rational person's hypothesis, the major shareholder as the main body of economic decision-making is full of reason, neither emotionally, nor obedient, but is adept at judging and calculating, and its behavior is rational. As a rational insider, a major shareholder will have its own interests when making decisions to reduce shareholdings. The majority shareholder judges that the company value is seriously high in the stock market based on the internal and external information obtained and the value of the individual. It is estimated that it is possible to make a decision to temporarily reduce excess earnings. Therefore, we make the following assumptions:

Hypothesis 1: The reduction of major shareholders has the signaling effect of transmitting overvaluation of the company, that is, if the major shareholders reduce their holdings, the greater the overestimation of the market value of the company. This article selects the company's Tobin Q value to indicate the company's valuation level. The higher the value, the higher the relative valuation of the company in the entire market.;

For some key industries related to the national economy and the people's livelihood, the Chinese government mostly adopts the form of controlling or equity participation in the control of key enterprises, and the increase and decrease of these enterprises are mainly considered from a strategic perspective. The state does not particularly care whether the value of these companies is Being overvalued in the stock market, so we put forward a second assumption:

Hypothesis 2: Compared with state-owned investors, the behavior of non-state-owned investors to reduce holdings is more informative.

Compared to natural person investors, non-natural person investors can obtain more insider information and make more accurate value judgments because of their financial and manpower advantages. Therefore, we propose Hypothesis 3:

Hypothesis 3: Compared with natural person investors, non-natural person investors have more information transfer effect than holding down shares.

\section{Research Design}

The Data Shows. This article selects companies with major shareholder reductions in all companies listed on the Shanghai and Shenzhen stock exchanges that have not been delisted during the 2012-2016 period as the original sample, and excludes financial and insurance companies, ST or $\mathrm{ST}^{*}$ companies and incomplete companies. Finally, the 1820 incidents of 683 listed companies were taken as samples. The research data in this paper comes from Guotai'an database, and data analysis uses SPSS software.

Table 1 Sample data statistics

\begin{tabular}{ccccccc}
\hline & 2012 & 2013 & 2014 & 2015 & 2016 & 合计 \\
\hline $\begin{array}{c}\text { Reduction ofState-owned } \\
\text { Major Shareholders }\end{array}$ & 33 & 42 & 56 & 60 & 23 & 214 \\
$\begin{array}{c}\text { Non-state-owned major } \\
\text { shareholder reduction }\end{array}$ & 196 & 415 & 419 & 303 & 273 & 1606 \\
$\begin{array}{c}\text { Total } \\
\text { Reducing holdings of }\end{array}$ & 229 & 457 & 475 & 363 & 296 & 1820 \\
non-natural big sharehold- & 170 & 246 & 268 & 224 & 141 & 1049 \\
$\begin{array}{c}\text { ers } \\
\text { Natural person shareholder } \\
\text { reduction }\end{array}$ & 59 & 211 & 207 & 139 & 155 & 771 \\
$\quad$ Total & 229 & 457 & 475 & 363 & 296 & 1820 \\
\hline
\end{tabular}

Model Design and Variable Definition. In order to test the transmission hypothesis of major shareholder reductions, the theoretical model variables for large shareholder reduction information transfer are defined as follows: 


\section{$Q=\alpha+\beta_{1} R E+\beta_{2}$ Size $+\beta_{3}$ DebtRatio $+\beta_{4} R O E+\beta_{5} S G R+\beta_{6} T A T+\varepsilon_{1}$}

\section{Explained variables: Tobin $\mathrm{Q}$}

The definition given by financial economists to corporate value is: the value of an enterprise is the present value of the expected free cash flow of the company discounted by its weighted average cost of capital. It is closely related to the financial decisions of the company and reflects the company's funds. Time value, risk, and ability to continue to develop. Expanding into the field of management, corporate value can be defined as the company's compliance with the law of value. Through value-based management, all stakeholders (including shareholders, creditors, managers, employees, and government, etc.) can be satisfied. ${ }^{[15]}$ Academia uses corporate performance indicators to represent company value. This paper selects Tobin $\mathrm{Q}$ as a measure of corporate performance. Tobin's $\mathrm{Q}$ value is the enterprise's market value compared to the enterprise's replacement cost. It is mainly used to evaluate the company's performance, growth, the company's investment value, the company's M \& A performance and management efficiency, and industrial effects.

2. Explanatory variables: Reduction of major shareholder (RE)

The "Measures for the Management of the Reform of Listed Company's Non-tradable Shares" requires that if the original non-tradable shares held by shareholders holding more than $5 \%$ of their shares are reduced to $1 \%$ of the total number of shares of the company, they should be 2 working days from the date of occurrence of the facts. An announcement is made within the company, and there is no need to announce the reduction of holdings of non-tradable shareholders holding less than $5 \%$ of shares. Therefore, we define major shareholders as all shareholders holding $5 \%$ or more of the total number of shares of the company. Taking into account the differences in the total number of shares and stock prices of companies of different sizes in different industries, this paper selects the percentage of major shareholders in the sample event to measure, ie, reduction of major shareholders $=$ number of shares reduced by major shareholders $/$ total number of shares of the listed company.

3, control variables:

Based on our previous research experience in reducing shareholder's shareholdings, we have selected the company size, asset-liability ratio, profitability index, development capability index, and operational capability index as control variables.

Table 2 Variable definitions

\begin{tabular}{cccc}
\hline \multicolumn{2}{c}{ Variable name } & Variable symbol & Variable definitions \\
\hline Explained variable & Company valuation & $\mathrm{Q}$ & $\begin{array}{c}\text { Market Value / (Total Assets - Net } \\
\text { Intangible Assets) }\end{array}$ \\
Explanatory variables & $\begin{array}{c}\text { Reduction of } \\
\text { major shareholders } \\
\text { Company Size }\end{array}$ & RE & $\begin{array}{c}\text { Large shareholders reduce the } \\
\text { number of shares / the total number } \\
\text { of shares of listed companies }\end{array}$ \\
& Assets and liabilities & LN (corporate assets) \\
Control variable & Profitability & Debt Ratio & Total liabilities / total assets \\
& ROE = Net Profit / Average \\
& Development ability & Shareholders Equity \\
& Operating capacity & SGR & Sustainable growth rate \\
& TAT & Total asset turnover
\end{tabular}

\section{Empirical Research Results and Analysis}

Descriptive Statistical Analysis. This article describes descriptive statistics on the reduction of major shareholders, and divides all data into three groups according to different classification conditions. First, the hypothesis is used for the analysis of all data, and then the hypothesis 2 divides the data into state-owned investors and non-state-owned enterprises. The qualitative investors conduct comparative analysis, and finally the data is divided into natural person investors and non-natural person investors for descriptive analysis to verify the correctness of hypothesis 3 .

Table 3 shows statistics of all data according to the year. It can be known that the number of re- 
duction samples reached the highest peak in 2014, and 475 listed companies issued reduction holding announcements; among which the minimum value of reductions occurred in 2013, and the maximum value appears. In the first four years of 2015, the overall trend of the average value is increasing, but the standard deviation is also increasing year by year. It can be seen that individual shareholder reduction efforts are increasing.

Table 3 Descriptive Statistics 1

\begin{tabular}{cccccc}
\hline & $\begin{array}{c}\text { Number of } \\
\text { samples }\end{array}$ & Min & Max & Average & Standard deviation \\
\hline 2012 & 229 & 0.00001 & 0.1071 & 0.0207964 & 0.0201625 \\
2013 & 457 & 0.00001 & 0.1186 & 0.0224573 & 0.0217954 \\
2014 & 475 & 0.00013 & 0.2436 & 0.0251309 & 0.0260573 \\
2015 & 363 & 0.00005 & 0.2697 & 0.0273859 & 0.0284366 \\
2016 & 296 & 0.00005 & 0.1498 & 0.0225546 & 0.0216922 \\
Total & 1820 & 0.00001 & 0.2697 & 0.0239449 & 0.0242706 \\
\hline
\end{tabular}

Table 4 Descriptive Statistics 2

\begin{tabular}{cccccc}
\hline & Number of samples & Min & Max & Average & Standard deviation \\
\hline $\begin{array}{c}\text { Reduction of state-owned } \\
\text { shareholders }\end{array}$ & 214 & 0.00005 & 0.1300 & 0.0194108 & 0.0183033 \\
$\begin{array}{c}\text { Reduction of } \\
\text { non-state-owned share- } \\
\text { holders }\end{array}$ & 1606 & 0.00001 & 0.2697 & 0.0244810 & 0.0248047 \\
\hline
\end{tabular}

Table 4 shows statistics according to state-owned shareholders and non-state-owned shareholders. We can see that the number of non-state-owned shareholders is significantly higher than that of state-owned shareholders, and the gap between the minimum value and the maximum value is also relatively large. In terms of value, non-state-owned shareholders have to reduce their holding power more than state-owned shareholders.

Table 5 Descriptive Statistics 1

\begin{tabular}{cccccc}
\hline & $\begin{array}{c}\text { Number of } \\
\text { samples }\end{array}$ & Min & Max & Average & Standard deviation \\
\hline $\begin{array}{c}\text { Reduction of Natural Per- } \\
\text { son Shareholders }\end{array}$ & 771 & 0.00002 & 0.1500 & 0.0224135 & 0.0206901 \\
$\begin{array}{c}\text { Reduction of non-natural } \\
\text { person shareholders }\end{array}$ & 1049 & 0.00001 & 0.2697 & 0.0249893 & 0.0263821 \\
\hline
\end{tabular}

Table 5 is the descriptive statistics of the reduction of natural person shareholders and the reduction of non-natural person shareholders. The number of non-natural person shareholder reductions is higher than that of natural person shareholders. From the perspective of the maximum, minimum and average, the reduction of non-natural person shareholders Overall, it is higher than natural person shareholders, but non-natural person shareholders have big differences in their shareholdings.

Correlation Analysis. The phenomenon that the model estimation is distorted or difficult to estimate due to the existence of an accurate correlation or highly correlated relationship among the explanatory variables in the linear regression model is called multicollinearity. Therefore, if the model has multiple collinearity, the results of the regression analysis become unreliable, so it is necessary to do a correlation test on the variables in the model.

Table 6 shows the results of the variable Pearson correlation test. It is generally believed that if the correlation coefficient exceeds 0.9 , there will be a problem of collinearity in the analysis. The results show that the correlation coefficient between experimental variables and control variables is low, and there is no multicollinearity problem in the preliminary judgment model.

In order to further test the rationality of the model, a collinearity diagnosis was made for all data. Multicollinearity increases the variance of the parameter estimates. If the variance inflation factor 
(VIF) is larger, the stronger the collinearity is. On the contrary, because the tolerance is the reciprocal of the variance expansion factor, the smaller the tolerance is, the stronger the collinearity is. In general, when $0<\mathrm{VIF}<10$, there is no multicollinearity; when $10 \leq \mathrm{VIF}<100$, there is strong multicollinearity; when $\mathrm{VIF} \geq 100$, there is severe multicollinearity. From the results of collinearity statistics, the VIF values of all variables are between 0 and 10 . Therefore, it is concluded that there is no multicollinearity in the model.

Table 6 Pearson correlation test

\begin{tabular}{ccccccc}
\hline & RE & Size & Debt Ratio & ROE & SGR & TAT \\
\hline RE & 1 & & & & & \\
Size & 0.058 & 1 & & & & \\
Debt Ratio & -0.080 & -0.460 & 1 & & & \\
ROE & 0.015 & 0.098 & 0.037 & 1 & & \\
SGR & -0.010 & -0.155 & 0.222 & 0.015 & 1 & \\
TAT & -0.002 & 0.081 & -0.174 & -0.158 & -0.072 & 1 \\
\hline
\end{tabular}

Table 7 Collinearity statistics

\begin{tabular}{ccc}
\hline Model & Tolerance & VIF \\
\hline RE & 0.993 & 1.008 \\
Size & 0.770 & 1.298 \\
Debt Ratio & 0.744 & 1.344 \\
ROE & 0.946 & 1.057 \\
SGR & 0.934 & 1.071 \\
TAT & 0.946 & 1.057 \\
\hline
\end{tabular}

Regression Analysis. Through calculations, the overall sample regression statistics result is shown in Table 8:

Table 8 The overall sample regression results

\begin{tabular}{ccc}
\hline \multirow{2}{*}{ Variables } & \multicolumn{2}{c}{ Total } \\
\cline { 2 - 3 } & Coefficient & Sig \\
\hline Constant & 20.047 & 0.000 \\
RE & $3.824^{*}$ & 0.058 \\
Size & $-0.786^{* * *}$ & 0.000 \\
Debt Ratio & $-1.169^{* * *}$ & 0.000 \\
ROE & $2.037^{* * *}$ & 0.000 \\
SGR & $2.612^{* * *}$ & 0.000 \\
TAT & $-0.276^{* * *}$ & 0.003 \\
\hline
\end{tabular}

Note: $* * *, * *, *$ are significant at the levels of $1 \%, 5 \%$, and $10 \%$, respectively

Table 9 Regression results of state-owned and non-state-owned samples

\begin{tabular}{|c|c|c|c|c|}
\hline \multirow{2}{*}{ Variables } & \multicolumn{2}{|c|}{ Non-state owned } & \multicolumn{2}{|c|}{ State owned } \\
\hline & Coefficient & Sig & Coefficient & Sig \\
\hline Constant & 20.718 & 0.000 & 21.166 & 0.000 \\
\hline $\mathrm{RE}$ & $4.085^{*}$ & 0.052 & -0.370 & 0.958 \\
\hline Size & $-0.817 * * *$ & 0.000 & $-0.851 * * *$ & 0.000 \\
\hline Debt Ratio & $-1.302 * * *$ & 0.000 & 0.257 & 0.568 \\
\hline ROE & $2.051 * * *$ & 0.000 & $1.158 * * *$ & 0.000 \\
\hline SGR & $3.138 * * *$ & 0.000 & $-1.221 * *$ & 0.048 \\
\hline TAT & $-0.246 * * *$ & 0.022 & $-0.334 * *$ & 0.044 \\
\hline
\end{tabular}

Table 8 shows the regression analysis of all the data. It can be seen that the regression coefficient of RE is significantly positive at the level of $10 \%$, which shows that there is a positive correlation between the share of reduction and the company Tobin's $Q$ value. Table 9 is a regression test of the 
reduction of state-owned large shareholders and non-state-owned large shareholders. The RE of non-state-owned large shareholders is positively related to Tobin's Q value at the $10 \%$ level, indicating that non-state-owned large shareholders can reduce their holdings. Pass the information that the corporate value is overestimated. Hypothesis 2 passes. Table 10 is the regression test of the reduction of holdings of natural persons' major shareholders and non-natural majority shareholders. The regression coefficient of non-natural majority shareholder RE has passed the test at the level of $5 \%$, indicating that the reduction of non-natural persons' major shareholders may indicate that The corporate value is overestimated, assuming three passes.

Table 10 Natural and non-natural sample regression results

\begin{tabular}{ccccc}
\hline \multirow{2}{*}{ Variables } & \multicolumn{2}{c}{ Natural person } & \multicolumn{2}{c}{ Non-natural person } \\
\cline { 2 - 5 } & Coefficient & Sig & Coefficient & Sig \\
\hline Constant & 16.202 & 0.000 & 20.952 & 0.000 \\
RE & -2.776 & 0.416 & $5.748^{* *}$ & 0.015 \\
Size & $-0.600^{* * *}$ & 0.000 & $-0.826^{* * *}$ & 0.000 \\
Debt Ratio & $-0.952^{* *}$ & 0.027 & $-1.134^{* * *}$ & 0.000 \\
ROE & $0.725^{* * *}$ & 0.000 & $2.031^{* * *}$ & 0.000 \\
SGR & $4.300^{* * *}$ & 0.000 & -0.412 & 0.303 \\
TAT & $-0.301^{*}$ & 0.055 & $-0.262^{* *}$ & 0.016 \\
\hline
\end{tabular}

Note: $* * *, * *, *$ are significant at the levels of $1 \%, 5 \%$, and $10 \%$, respectively

\section{Conclusions and Suggestions Research Conclusions}

This article uses the publicly disclosed holdings announcement data in the A-share market to conduct a comprehensive observation and analysis of the reduction of the company's Tobin Q value and related factors between 2012 and 2016. It is found that the value of the company is overvalued and the major shareholder is reduced. The positive correlation between the holdings shows that the reduction of major shareholders can convey the conclusion that the value of the company is overvalued. From this further analysis, it was found that, compared with state-owned large shareholders, the reduction of non-state-owned large shareholders can better convey the information that the value of the company is overvalued, and that it is even better for the non-natural majority shareholders to reduce their holdings than the natural majority shareholders. Delivering information that the company's value is overvalued. In addition, the overestimation of corporate value is also affected by total corporate assets, sustainable growth rates, and total asset turnover.

According to the research conclusion, investors can judge whether the value of their own stocks is overvalued by analyzing the holdings of the company's major shareholders, so that they can choose to increase or reduce their positions in a timely manner. In particular, they should pay close attention to non-state-owned large shareholders and non-natural large shareholders. The increase and decrease in the holding trend, their reduction behavior can convey more corporate value information. The supervisory department can also pay close attention to the reduction of holdings by major shareholders of the company to prevent the large shareholders from illegally drawing funds to harm the rights and interests of small and medium shareholders. In addition to this, it should also improve the administrative regulations for reducing shareholder's shareholdings to regulate the reduction of holdings by major shareholders.

\section{References}

[1] Gao Yan, Yang Tong, Zheng Gantian et al. Study on the status quo and influencing factors of shareholder reduction in the context of full circulation[J]. Macroeconomic Research, 2016(8):107-115.

[2] Lin Chuan, Cao Guohua. Earnings management, non-annual report effect and major shareholder reduction [J]. Southern Economy, 2012, (12): 18-35.

[3] Chen Wei, Wu Shinong. The motivation and consequence of the reduction of shares held by executives and large shareholders of listed companies on China's ChiNext market - from risk 
appetite to risk aversion "preference reversal" behavior research [J]. Economic Management, 2013, (06): 43-53.

[4] Zhang Chengrui, Wang Hua, and Liang Sanning. Research on the behaviors and incentives of the original shareholder holding shares with restricted sales[J]. Economic Management, 2016,(06):111-124.

[5] Deng Mingmao. Study on Opportunities for Reducing Shareholders and Targeted Arbitrage Behaviors of Major Shareholders[J]. Auditing and Economic Research, 2016,(03):73-82.

[6] Lin Zhenxing, Qu Wenzhou. Reduction of Holding Shareholders' Opportunity and Opportunity - Based on the Empirical Study of Large Stocks in Shanghai and Shenzhen Stock Markets[J]. Securities Market Herald, 2010, (10): 71-77.

[7] Fu Liping, Zhang Dayong. Empirical Study on the Tunneling Behavior of Large Shareholders in the Reduction of Shareholdings[J]. Finance and Economics Theory \& Practice, 2011, (05):39-43.

[8] Wu Yuhui, Wu Shinong. Research on Big Shareholders' Short Selling Behavior in Stock Reduction Process[J]. China Industrial Economy, 2010,(05):121-130.

[9] Zhu Hongjun, Li Lu, Wang Hui, et al. Market Reaction and Shareholder Behavior Model of Selling Stock Reducing Shares Reduction[J]. China Accounting and Finance Research, 2010(4):142-199.

[10]Zhu Chafen, Li Zhiwen, Chen Chao. The Opportunity of the Major Shareholders' Reduction in A Share Market and Market Response Study [J]. Journal of Zhejiang University (Humanities and Social Sciences), 2011, (03): 159-169 . [11] Jasmin Gider,Christian Westheide. Relative idiosyncratic volatility and the timing of corporate insider trading $[\mathrm{J}]$. Journal of Corporate Finance, 2016.

[11]Liu Jinxing, Song Lisheng. An Empirical Study on Timeliness of Insider Trading Information Disclosure[J]. Journal of Shanxi Finance and Economics University, 2015,(01):70-80.

[12] David J.Denis, Jin Xu, Insider trading restrictions and top executive compensation [J].Journal of Accounting and Economics 56(2013)91-112.

[13] J.Lakonishok \& I.Lee, “Are Insider Trades Infoemative?” Review of Financial Studies, Vol.14, No.1(2001)

[14]Encyclopedia of Wikipedia "Enterprise Value" entry. http://baike.so.com/doc/6694890-6908799.html 